Article

\title{
Thriving Organizational Sustainability through Innovation: Incivility Climate and Teamwork
}

\author{
Jaewan Yang \\ College of Business, Hankuk University of Foreign Studies, 107 Imun-ro, Dongdaemun-gu, Seoul 02450, Korea; \\ jwyang@hufs.ac.kr; Tel.: +82-2-2173-3471
}

Academic Editor: Marc A. Rosen

Received: 27 June 2016; Accepted: 22 August 2016; Published: 29 August 2016

\begin{abstract}
The present study examines the association between team incivility climate and team members' perceived support for innovation. To extend findings on the negative effects of incivility (which are low intensity deviant behaviors, such as rudeness) in studies focusing on the individual level, the effects of organizational incivility are examined at the work team level. Drawing on the spiral model of incivility and the literature on teams, this study suggests that team incivility climate has a negative impact on perceived support for innovation through team members' teamwork behaviors. Using data collected from 411 subordinates on 62 work teams, the hypothesized mediation model is tested. The results show a negative effect of team incivility climate on teamwork and a positive effect of teamwork on perceived support for innovation, supporting the hypothesized negative indirect effect. Research and practical implications for organizational sustainability are discussed.
\end{abstract}

Keywords: organizational sustainability; incivility climate; deviance; teamwork; support for innovation

\section{Introduction}

According to Andersson and Pearson [1] (p. 457), workplace incivility can be defined as "low-intensity deviant behavior with ambiguous intent to harm the target, in violation of workplace norms for mutual respect. Uncivil behaviors are characteristically rude and discourteous, displaying a lack of regard for others". This type of behavior falls under the domain of "dysfunctional work behavior". Dysfunctional behaviors include physical aggression and psychological injury such as violence, aggression, bullying, deviance, and harassment [2]. Although incivility overlaps somewhat with other forms of dysfunctional behavior, it is subtle and ambiguous in terms of the instigators' intention compared with other, more aggressive and intentional forms of dysfunctional behavior. Andersson and Pearson [1] conceptualized workplace incivility as a sub-type of employee deviance [3] that exemplifies antisocial employee behavior [4].

The growing interest in this topic [2,5-7] is not surprising considering the deleterious effect of uncivil behaviors on individuals and organizations. One study acknowledged that targets of incivility intentionally decreased their work effort (48\%), time (47\%), and work quality (38\%), and many lost work time worrying about the incident (80\%) [6]. Moreover, those who become the targets of uncivil behaviors experience emotional distress [2] and deterioration of their psychological well-being [8], and they are more likely to leave the organization $[9,10]$. However, the effect of incivility is not limited to the targets. Research findings have also shown that treating others unfairly increased participants' own negative emotions and decreased their organizational citizenship behaviors (OCBs) [11], and observers of uncivil behaviors are also affected by these incidents [11,12]. These findings suggest that managing workplace incivility costs organizations time, energy, and money. For example, one article in Fortune reported that executives at Fortune 1000 firms spent approximately 13\% of their work time mending employee relationships and addressing the aftereffects of incivility [6]. 
Although these findings are useful, more studies on this topic are needed to effectively address the negative effect of incivility on organizations. Given that incivility studies have primarily been conducted at the individual level [13], the findings so far do not necessarily provide important insights about how incivility operates in team contexts. Individuals are bound by the organizational context in their behaviors [14], and importantly, findings at the individual level should not be assumed to be equivalent at other levels [15]. Thus, an examination of workplace incivility at the team level is needed because the use of team practices is currently prevalent, and such practices are critical to the success (or survival) of organizations $[16,17]$.

Examining the relationship between incivility and innovation at the team level is particularly useful given that organizational innovation is frequently considered a collective initiative of members who are involved in the process. It is often the case that organizational innovation is originated and developed by work teams and is subsequently routinized into practice within organizations [18,19]. Thus, group-level predictors that facilitate or prohibit collective work behaviors can provide meaningful insights into organizational innovation and sustainability. In that sense, a team-level incivility climate can provide context for reduced coordinated work behaviors that are necessary to promote work team-driven organizational innovation. Moreover, the low intensity of work place incivility makes this topic more important to examine at the collective level. Unlike more aggressive forms of counter-productive work behaviors (e.g., violence, aggression), uncivil behaviors are less visible, and are thus more likely to quickly spread within work teams without being explicitly recognized, stopped, or effectively managed by team members or managers.

Drawing on the spiral model of incivility [1], this study examines the effects of incivility climate on employee perceptions of innovation support through the mediating mechanism of teamwork behaviors to investigate the relationship between incivility climate and innovation from the perspectives of work team members. Specifically, it is expected that team incivility climate will have adverse effects on teamwork behaviors, which will subsequently reduce levels of team members' perceived innovation support. Additionally, a direct association between incivility climate and perceived support for innovation has also been hypothesized. Data collected from 411 employees nested in 62 work teams are used to examine the relationships hypothesized in this study.

By doing so, this study aims to contribute to the incivility and the innovation and sustainability literature in three ways. First, this study examines the impact of incivility at the group level rather than at the individual level. It is important to examine the impact of a "climate" for incivility on work groups because it has potentially negative impacts on people who are not directly involved in uncivil events. Second, the study identified teamwork as a mediating mechanism between team incivility climate and employees' perceived support for innovation. Unlike individual-level explanations (e.g., psychological process) of the negative impact of incivility, this study employed one of the core group processes (i.e., teamwork) as a mediating mechanism in the relationship between incivility and perceptions of innovation support. Finally, this study expands the utility and applicability of team-level climate research by adding team incivility climate as a potential factor that affects various work team processes.

\section{The Emergence of Team Incivility Climate}

Incivility has been conceptualized as an individual-level construct, and to date, researchers have focused on finding predictors and outcomes at the individual level $[1,2,5,7,12]$. However, sufficient theoretical and empirical evidence suggests the existence of incivility as a group-level construct. Morgeson and Hofmann [20], in their article explaining how a collective-level construct emerges, argued that collective actions are the results of a series of ongoing events and event cycles that create shared understandings among organizational members. Given that individuals are subject to their work environment, their perceptions and interpretations of certain events are likely to be influenced by the perceptions of others who work closely with them. 
This rationale offers a potential explanation for how team members develop shared meanings and understandings about incivility in their work groups. Uncivil behaviors are presumed to develop through the "incivility spiral" suggested by Andersson and Pearson [1]. When uncivil events occur, the victims of uncivil behaviors respond in several ways. Although some victims try to defend themselves by avoiding the instigators, other victims plan for retaliation or revenge [21]. This vicious cycle results in tit-for-tat spirals of dysfunctional uncivil behaviors [1]. Increases in the frequency of uncivil behaviors through incivility spirals escalate the degree of incivility and can eventually create an uncivil climate within work teams. This process is consistent with the emergence of workplace climate through a series of ongoing events, as suggested by Morgeson and Hofmann [20].

Team settings intensify the emergence of incivility even further, as shown in a study that examined dysfunctional behaviors at the team level [13]. Social learning theory [22] proposes that individuals model each other's actions after observing their behaviors. Drawing on social learning theory, the interactive and coordinated nature of team settings presumably becomes a powerful vehicle for team members to model uncivil behaviors for other members. This mechanism is consistent with the "spillover effect," which suggests that individuals become more mentally accessible when they observe their teammates acting in certain ways $[23,24]$. In previous studies of workgroup aggression, the spillover effect has been described as "contagious aggression," in which instigators set off team members one after another $[13,25,26]$.

Based on the explanations above, team incivility climate can be defined as the "shared perception by team members that subtle and trivial rudeness is pervasive in work teams". This definition is consistent with individual-level constructs but still distinctive in that the team's uncivil climate shapes individuals' tendency to engage in uncivil behaviors or affect the psychological well-being of other team members. Additionally, conceptualizing incivility as a team-level climate variable responds to the mounting calls for team-level studies on work events and performance [27] and for more specific climate constructs such as a safety climate [28] or a climate for service [29]. Although incivility climate can be conceptualized as a business unit-(or organization-)level construct [30], focusing on the team-level climate has an advantage. The existence and effect of an uncivil climate is likely to be more robust at the team level because members are subject to intense interactions with each other that enable a stronger climate to develop.

\section{Hypotheses}

At the individual level, previous studies on incivility found that victims of uncivil behaviors are likely to reduce their helping behaviors toward others [2,7,12]. Specifically, the findings indicated that victims showed low levels of cooperation, volunteering, and helping behaviors after having experiences with uncivil behaviors. For example, Porath and Erez [7] found that several different forms of rudeness (e.g., rudeness instigated by a direct authority figure or a third party and imagined rudeness) reduced helping behaviors by the subjects in their study. They suggested that helping behaviors are reduced because (1) incivility undermines the norm of positive reciprocity by which people help those who benefit them; and (2) victims do not feel obligated to help those who mistreat them even though helping others is socially considered the right thing to do. Importantly, the effect was not limited to the instigators of uncivil behaviors. The targets also withheld helping behaviors from others who were not directly involved in uncivil events.

Although these findings are based on individual-level studies, they can be useful for understanding how incivility affects the team level. As the emergence of incivility climate within work teams indicates, individuals who are not directly involved in uncivil events are more likely to reduce cooperation, volunteering, and helping behaviors toward others under high levels of incivility climate. The quality of co-worker relationships reflects levels of work behaviors such as helping, communication, and coordination among employees engaged in inter-dependent tasks [31]. This notion of co-worker relationship quality was identified with "teamwork/conflict" in a study by Glaser et al. [32] (p. 194). According to this study, teamwork can be defined as "reported 
coordination of effort, interpersonal cooperation, rapport, or antagonism, resentment, jealousy, mistrust, power struggle between sections or divisions; (and the extent to which) people talk directly and candidly about problems they have with each other".

Teamwork behavior is considered an effective way to create synergy in work teams. The input-process-output (IPO) model [33] suggests that a work team can achieve team effectiveness by creating team synergy through the mechanism of process gain and loss. Teams can maximize process gain and minimize process loss to maintain high levels of teamwork through members' cooperation with colleagues, volunteering for tasks that go beyond their formal work requirements, and exhibiting helping behaviors toward others. In this respect, the potential effect of incivility climate within a workgroup is significant because work teams experience low levels of communication and coordination, which are the core ideas behind teamwork behavior [34], under a strong climate of incivility. Subsequently, this climate results in process loss in the form of decreased teamwork behaviors within work teams.

There is also another explanation for reductions in teamwork behaviors under high levels of incivility. Porath and Pearson [6] proposed a reduction in "psychological safety" as a potential explanation. In their study, they observed that uncivil behaviors squandered team productivity because members reduced their work effort and obstructed the flow of information. Moreover, nearly one-fifth of the respondents actually refused to work with people who mistreated them and stopped offering to help them, which occurs because members are less likely to seek and accept feedback, ask for help, or inform each other about potential problems under high levels of team incivility. In other words, members will be less likely to engage in interactions with other people when they feel psychologically unsafe.

Hypothesis 1: Team incivility climate is negatively associated with teamwork behavior.

Innovation can be defined as "the internal introduction and application within a role, group or organization of ideas, processes, products or procedures, new to the relevant unit of adoption, designed to significantly benefit role performance, the group, the organization or the wider society" [35] (p. 16). The growing interest in innovation is not surprising and indispensable to nurture sustainable organizations given the rapidly changing business environment and heightened competition in the market. Conducting studies at the group (team) level of analysis is particularly useful and needed because innovation is frequently initiated and developed by work teams $[18,19,36]$. The current study focuses on examining the effects of an uncivil team climate on team members' perceived support for innovation [37] via teamwork behaviors. Incivility (e.g., not helping) is expected to impact perceived support for innovation that originates from colleagues in the same work group.

Support for innovation is understood as "... the expectation, approval and practical support of attempts to introduce new and improved ways of doing things in the work environment" [18] (p. 38). Employees' perceived support for innovation is considered a necessary condition for innovation [37]. For example, enacting the support of senior executives who are willing to serve as a project champion is important in implementing innovative ideas [38,39]. High-ranking authorities can use their power to address the forces resisting or unwilling to follow the new direction of their organizations or offer needed resources. However, the support of members within the work group is also critical. Amabile [38] emphasized that innovation is a process of implementing creative ideas. In nature, implementing new ideas requires intensive interactions between people who are involved in the process. Thus, superior teamwork behavior can be an excellent source of perceived support for innovation.

In addition, effective learning experiences occurring in multiple ways through intensive interactions with team members can nurture a sense of support for innovation. The literature on perceived organizational support (POS) provides explanations for how such experiences can happen. Eisenberger et al. [40] proposed POS as employees' global perceptions regarding the extent to which their organization values their contributions and cares for their well-being. The theory 
indicates that employees develop high levels of POS when organizations provide employees with the support needed to complete tasks in multiple ways. In two empirical studies, formal and informal development experiences have been identified as predictors of POS [41,42]. Team members can have developmental experiences through frequent and open communication, well-structured and synchronized coordination, and mutual support for the completion of tasks through intensive interaction. When team members experience high-quality learning by engaging in innovative tasks that are naturally subject to an interdependent work structure, they are likely to perceive high levels of organizational support that is geared toward organizational innovation.

Hypothesis 2: Teamwork behavior is positively associated with perceived support for innovation.

Hypothesis 3: Teamwork behavior mediates the relationship between team incivility climate and perceived support for innovation.

Although the effect of team incivility climate on perceived support for innovation may occur indirectly through teamwork, a direct relationship can also be hypothesized. Traditionally, innovation was considered the result of sudden insight [43]. However, current accounts suggest that this sudden emergence of a creative idea requires extensive attention and effort [7]. Several studies [7,12] have suggested that experiencing incivility (being a target or observing uncivil behaviors) distracts individuals from the tasks at hand. Such distractions occur because uncivil events draw people's attention, leading them to experience reduced levels of cognitive resources. When employees are frequently distracted by unpleasant and rude behaviors in their team, they are less likely to feel that they are receiving the support they need for innovation [44].

Hypothesis 4: Team incivility climate is negatively associated with perceived support for innovation.

\section{Method}

\subsection{Research Setting}

The data were collected in Mainland China with the cooperation of 14 different organizations that represent service and manufacturing industries. For data collection, several research assistants who were enrolled in a master's program at a large Chinese university visited the sample organizations to administer the survey and maintain the confidentiality of the responses. Because all of the survey questions were originally developed in English, the questions were translated into Chinese and back-translated into English to ensure the translation's accuracy [45]. The data were collected from two different sources to reduce the problem of common source bias. Team managers answered questions related to perceived support for innovation, whereas employees answered questions regarding incivility and teamwork behaviors. To further minimize common method bias, the sample was randomly split in half. Specifically, half of the sample was used to create the team incivility climate variable whereas the other half was used to create the teamwork behavior variable.

From the collected surveys, the sample was limited to groups with at least four subordinate responses from each team. The final sample included 411 subordinates from 62 work teams. The average group size was 6.63 per group. Of the subordinates, $52.60 \%$ were male and $44.50 \%$ were female, with $2.90 \%$ unanswered. The average tenure was 6.02 years. Approximately $40.00 \%$ of the sample had an associate's degree, and $23.90 \%$ had earned a bachelor's degree or above. In terms of supervisors, the gender composition was $61.30 \%$ male and $33.90 \%$ female, with $4.80 \%$ unanswered. The average tenure was 10.98 years. With regard to education, $22.00 \%$ of the manager respondents had an associate's degree, and $70.90 \%$ had completed their bachelor's degree or above.

\subsection{Measures}

Team incivility climate. To measure team incivility climate, the five items from Bennett and Robinson's [46] measure of interpersonal deviance were used. The incivility construct is fully encompassed by the interpersonal deviance construct [1]. The only difference between the two constructs 
is that interpersonal deviance can include more severe behaviors than incivility. To avoid capturing severe interpersonal behaviors, the following two items were excluded: "publicly embarrassed someone at work" and "made an ethnic, religious, or racial remark at work". Moreover, the latter item was considered inappropriate because the sample organizations did not include any non-Chinese workers. For all items used to measure incivility, the reference was shifted [47] as a way to capture incivility climate as a group-level construct. Because this variable was measured at the individual level, aggregation statistics were calculated. ICC(1) is a measure of intra-class correlation representing the variance of the variable that can be explained by group membership [48], and $r_{\mathrm{wg}}$ is a measure of agreement that suggests the level of agreement for the measure across members of the work group [49]. ICC(1) was 0.22 and was within the recommended cut-off of 0.05 [49]. The median $r_{w g}$ score was 0.70 and was within the recommended cut-off of 0.60 [48]. Cronbach's alpha for this measure was 0.93.

Teamwork behaviors. This variable was measured using a six-item scale developed by Glaser et al. [32]. This measure captures group-level coworker communication, cooperation, and helping behavior. Subordinates were used as the source for this variable. Because this variable was also measured at the individual level, aggregation statistics were calculated. ICC(1) was 0.04 , and $\mathbf{r}_{\mathrm{wg}}$ was 0.91 . Although the value of ICC(1) was below the recommended cut-off, the cut-off cannot be used as a definitive criterion, and this slight difference should not prevent aggregation [50]. Because $r_{w g}$ was sufficiently high at 0.91, the one-way ANOVA, which is used to calculate ICC scores, was statistically significant $(p<0.05)$. The Cronbach's alpha for this measure was 0.93 .

Perceived support for innovation. Perceived support for innovation was measured using the items suggested by Anderson and West [37]. The authors suggested four sub-dimensions of innovation to capture an individual's perceptions about innovation. Among those, the eight items that were designed to measure support for innovation were used. Respondents were the supervisors of the subordinates who responded to the team member survey. Supervisors were used as the source of this measure because (1) supervisors can perceive the level of support among employees; and (2) supervisors can reduce potential impact of common source variance between teamwork behavior and perceived support for innovation. In the case of individual-level analysis, it is more logical to collect this information from subordinates who provide the other variables. However, in the current group-level analysis, the use of supervisors as the source of this measure can be useful because supervisors are also members of their work team and oversee interactions among all team members. The Cronbach's alpha for this measure was 0.94 .

Control variable. To consider alternative explanations for the hypothesized model, team size was included as a control variable. In many previous studies conducted at the team level, the size of a work team was a significant predictor of multiple types of team performance measures [17]. Thus, this variable was included to strengthen the study's findings.

\section{Results}

To analyze the hypothesized model, SPSS (Statistical Package for the Social Sciences) was used. The zero-order correlations, standard deviations, and means for the variables included in the hypothesized model appear in Table 1.

Table 1. Correlations and Descriptive Statistics.

\begin{tabular}{lccccc}
\hline \multicolumn{1}{c}{ Variable } & Mean & SD & $\mathbf{1}$ & $\mathbf{2}$ & $\mathbf{3}$ \\
\hline 1. Team size & 9.56 & 5.78 & & & \\
2. Team incivility climate & 2.09 & 0.75 & 0.23 & & \\
3. Teamwork & 4.26 & 0.40 & $-0.32 *$ & $-0.27^{*}$ & \\
4. Perceived support for innovation & 4.11 & 0.72 & -0.12 & -0.15 & $0.38^{* *}$ \\
\hline
\end{tabular}

Note: $N=55-62 ;{ }^{*} p<0.05$ (two-tailed); ${ }^{* *} p<0.01$ (two-tailed). 
The suggested model was tested using hierarchical linear regression analysis. Table 2 shows the results of testing Hypotheses 1, 2, and 3. To test Hypothesis 1, teamwork behavior was regressed on team size in Model 1 . This model explained approximately $4 \%$ of the total variance in teamwork behavior. In Model 2, team incivility climate was added to the previous model (Model 1). The result showed that team incivility climate was a significant predictor of teamwork behavior $(b=-0.14, p<0.05)$. Model 2 explained an additional $4 \%$ of the variance of the criterion variable. In total, this model explained $8 \%$ of the total variance in teamwork $(p<0.05)$. Thus, Hypothesis 1 was supported.

Table 2. Results of Hierarchical Regression Analysis Testing of H1, H2, and H3.

\begin{tabular}{ccccccc}
\hline \multirow{2}{*}{ DV $=$} & \multicolumn{2}{c}{ Teamwork } & & \multicolumn{3}{c}{ Perceived Support for Innovation } \\
\cline { 2 - 3 } \cline { 6 - 7 } & Model 1 & Model 2 & & Model 4 & Model 5 & Model 6 \\
\hline Team size & -0.01 & -0.01 & & 0.01 & 0.01 & 0.00 \\
Team incivility climate & & $-0.14^{*}$ & & & $0.69^{* *}$ & -0.14 \\
Teamwork & & & & $0.15^{* *}$ & 0.02 \\
R-squared & 0.04 & $0.08^{*}$ & & 0.00 & $0.15^{* *}$ & 0.02 \\
\hline
\end{tabular}

Note: $N=55-62{ }^{*} p<0.05$ (two-tailed); ${ }^{* *} p<0.01$ (two-tailed).

The procedure used to test Hypothesis 2 was the same as that for Hypothesis 1. In Model 3, perceived support for innovation was regressed on team size in Model 3. This model explained almost none of the variance in perceived support for innovation. In the subsequent analysis (Model 4), teamwork behavior was added to Model 3. The results indicated that teamwork behavior is significantly associated with perceived support for innovation $(b=0.69, p<0.01)$. Specifically, teamwork explained an additional $15 \%$ of the total variance of the criterion variable $(p<0.05)$. Thus, the total variance explained in Model 4 can be attributed to teamwork behavior, and Hypothesis 2 was supported. However, Model 5, which tested the direct effect of team incivility climate on perceived support for innovation, was not significant. Thus, Hypothesis 4 was rejected.

In terms of testing mediation, a bootstrap analysis was conducted [51]. An increasing number of recent studies testing mediation analysis are adopting this approach $[52,53]$, which has an advantage in testing mediation compared with more traditional approaches (e.g., Sobel test). Specifically, the bootstrap approach is not subject to the assumption of a standard distribution and generates more robust standard errors [54]). Thus, it can offer more accurate confidence intervals for testing the indirect effects of hypothesized mediation models [51]. To test the indirect effect of team incivility climate on members' perceived support for innovation via teamwork behavior, 5000 hypothetical samples were generated. The bootstrap result (Table 3) showed that the indirect effect was -0.09 . Specifically, the indirect effect was statistically significant with $95 \%$ (two-tailed) confidence intervals $(\mathrm{LLCI}=-0.27, \mathrm{ULCI}=-0.01)$ and did not include zero in the estimation of the bias-corrected percentile test [55]. Therefore, Hypothesis 3 was supported.

Table 3. Bootstrap Analysis Result for the Indirect Effect of Team Incivility Climate on Perceived Support for Innovation.

\begin{tabular}{ccccc}
\hline Indirect Effect & Boot Indirect Effect & Boot SE & Boot Lower CI & Boot Upper CI \\
\hline $\begin{array}{l}\text { Team incivility climate } \rightarrow \text { Teamwork } \\
\rightarrow \text { Perceived support for innovation }\end{array}$ & -0.09 & 0.06 & -0.27 & -0.01 \\
\hline
\end{tabular}

Note: $\mathrm{CI}=95 \%$ confidence interval (two-tailed); Bootstrap sample size $=5000 ; \mathrm{N}=60$. 


\section{Discussion}

Drawing on the spiral model of incivility [1] and the literature on work teams [33], this study proposed and found that team incivility climate undermines the quality of teamwork behavior. It seems that members experience reductions in communication, coordination, and helping behaviors under the presence of an incivility climate. Moreover, teamwork behavior was determined to be a significant predictor of perceived support for innovation. To reinforce this finding, a post hoc analysis was conducted to examine Hypothesis 2 with perceived support for innovation measured from employees. The analysis showed that the finding was consistent $(b=0.75, p<0.01)$ with the previous finding. Although this finding is subject to the threat of common source variance, the variable explained much more variance than the supervisor-rated variable ( $R$-squared increase $=0.55)$. Taken together, these findings suggest a negative indirect effect of team incivility climate on perceived support for innovation.

However, the analysis also indicates that there was no direct association between team incivility climate and perceived support for innovation, although the direction of the association was negative, as expected. However, the association may be significant in a study with a larger sample because the small sample size might have been a problem. It is also possible that the use of supervisor ratings for the variable weakened the relationships as a way to overcome the limitation of common source variance. Measuring support for innovation from subordinates might make the association stronger. Thus, another post hoc analysis was conducted to estimate the direct link between incivility climate and employee-rated perceived support for innovation. The result showed a statistically significant association $(b=-0.22, p<0.01)$, and the increase in R-squared was 0.26 , although this finding is subject to common source bias.

\section{Research and Practical Implications}

Arguably, this is the first team-level study of organizational incivility. In contrast to previous individual-level studies, the current study focused on the impact of "shared" perceptions of team members on a work team process, such as teamwork behavior. Although findings from individual-level studies are useful, it is still important to examine the meanings and implications of organizational incivility at the work group (team) level. The impact of incivility can spread to the whole work team, even those members who are not involved in the events, very quickly without being explicitly recognized or managed. Thus, incivility climate has high potential to be destructive to team-driven organizational innovation and sustainability. By shifting the research focus to the group level, this study identified reductions in teamwork behaviors as an important group-level mechanism on the negative relationship between team incivility climate and team innovation.

Moreover, this study expands the utility and applicability of team-climate research by adding to current research on team-level climate. Previous studies found that workplace climate factors, such as innovation [37], safety [28], justice [17], and service [56], have significant effects on work process. The current findings suggest that incivility climate at the work team level can have significant impacts on work processes such as teamwork behavior. Team incivility climate may be associated with other team-level attitudinal or behavioral process and performance outcomes, such as team commitment, collective efficacy, sub-group conflict, communication, or work performance.

The conceptual framework and findings of this study have implications for management practices as well. Organizations are advised to be proactive to prevent uncivil behaviors within their organizations by focusing on the role of supervisors. Supervisors can be considered the first line of defense to prevent the emergence of uncivil organizations where uncivil behaviors exist. When supervisors do not take uncivil behaviors within their teams seriously, their work teams are vulnerable to the development of a strong climate of incivility. Top managers and human resource management officers should not only prevent uncivil practices with effective organizational rules and procedures but also ensure that supervisors take proactive roles to prevent uncivil behaviors. 
It is recommended that organizations provide supervisors with training in coaching. Some people may commit uncivil acts because they do not understand what it means to be civil, or they do not know how to behave better [6]. To prevent the development of an uncivil climate in teams, supervisors not only need to pay special attention to this issue but also should have a solid understanding of how to address it. Specifically, supervisors must know how to observe uncivil conduct, listen to signals for help, and offer to help to prevent incivility. In addition, with training in coaching, supervisors can teach their members how to be more respectful of their coworkers. During supervisor training, supervisors should be provided with a well-developed organizational policy or manual regarding issues relating to incivility.

\section{Conclusions}

With the intention of investigating how the frequent occurrence of uncivil behaviors within work groups impacts important work processes at the team level, I tested how team incivility climate affects teamwork behavior and perceived support for team innovation, which would eventually impact organizational sustainability. In conclusion, the study showed that the prevalence of uncivil behaviors undermines the teamwork process, thereby leading to members' poor perceptions of support for innovation. The results add to the previous findings in incivility research that mainly focus on individual-level relationships between variables. Furthermore, the study provides potentially meaningful directions for future research to investigate the effects of uncivil behaviors conceptualized at other levels of analysis, such as the team or organization levels, and the function of other important process mechanisms that can explain the effect of these higher-level constructs of incivility on various work outcomes.

\section{Limitations and Future Research}

The data used in the study were collected in Mainland China. China is considered to be a highly collectivist culture [57], and "saving face" is extremely important for people when they engage in social activities in this culture. Thus, being a target of or a witness to uncivil behaviors may have a stronger impact on individuals in China than it would in a more individualist culture. Second, the inability to test for causal relationships between the variables is another limitation of the study. Because of a cross-sectional design of the study, testing the causal relationships was impossible. Finally, a small sample size must be considered another limitation of the current study. The direct relationship between incivility climate and perceived support for innovation may turn out to be statistically significant using a larger sample.

In future studies, it would be useful to test the impact of team incivility climate on other team-level process or outcome variables. For example, the emergence of team incivility climate might cause sub-group formation [58] in work groups. It is also expected that the effect of team-level incivility on team-level outcomes is subject to boundary conditions. Several individual-level studies found that the impact of uncivil or dysfunctional behaviors is dependent on individual pro-social value orientation [12], nonverbal negative expressivity [13], and negative affectivity [59]. Conducting group-level studies to identify boundary conditions for the impact of incivility climate would be worthwhile.

Acknowledgments: This work was supported by Hankuk University of Foreign Studies research fund of 2016.

Conflicts of Interest: The author declares no conflicts of interest.

\section{References}

1. Andersson, L.M.; Pearson, C.M. Tit for tat? The spiraling effect of incivility in the workplace. Acad. Manag. Rev. 1999, 24, 452-471.

2. Cortina, L.M.; Magley, V.J; Williams, J.H.; Langhout, R.D. Incivility in the workplace: Incidence and impact. J. Occup. Health Psychol. 2001, 6, 64-80. [CrossRef] [PubMed] 
3. Robinson, S.L.; Bennett, R.J. A typology of deviant workplace behaviors: A multidimensional scaling study. Acad. Manag. J. 1995, 38, 555-572. [CrossRef]

4. Giacalone, R.A.; Greenberg, J.E. Antisocial Behavior in Organizations; Sage Publications: Thousand Oaks, CA, USA, 1997.

5. Lim, S.; Cortina, L.M.; Magley, V.J. Personal and workgroup incivility: Impact on work and health outcomes. J. Appl. Psychol. 2008, 93, 95-107. [CrossRef] [PubMed]

6. Porath, C.L.; Pearson, C.M. The cost of bad behavior. Organ. Dyn. 2010, 39, 64-71. [CrossRef]

7. Porath, C.L.; Erez, A. Does rudeness really matter? The effects of rudeness on task performance and helpfulness. Acad. Manag. J. 2007, 50, 1181-1197. [CrossRef]

8. Einarsen, S.; Raknes, B.I. Harassment in the workplace and the victimization of men. Violence Vict. 1997, 12, 247-263. [PubMed]

9. Kamp, J.; Brooks, P. Perceived organizational climate and employee counter productivity. J. Bus. Psychol. 1991, 5, 447-458. [CrossRef]

10. Neuman, J.H.; Baron, R.A. Aggression in the workplace. In Antisocial Behavior in Organizations; SAGE Publications, Inc.: Thousand Oaks, CA, USA, 1997; pp. 37-67.

11. De Cremer, D.D.; Van Hiel, A.V. Effects of another person's fair treatment on one's own emotions and behaviors: The moderating role of how much the other cares for you. Organ. Behav. Hum. Decis. Process. 2006, 100, 231-249. [CrossRef]

12. Porath, C.L.; Erez, A. Overlooked but not untouched: How rudeness reduces onlookers' performance on routine and creative tasks. Organ. Behav. Hum. Decis. Process. 2009, 109, 29-44. [CrossRef]

13. Cole, M.S.; Walter, F.; Bruch, H. Affective mechanisms linking dysfunctional behavior to performance in work teams: A moderated mediation study. J. Appl. Psychol. 2008, 93, 945-958. [CrossRef] [PubMed]

14. Kozlowski, S.W.; Hattrup, K. A disagreement about within-group agreement: Disentangling issues of consistency versus consensus. J. Appl. Psychol. 1992, 77, 161-167. [CrossRef]

15. Kozlowski, S.W.; Klein, K.J. A multilevel approach to theory and research in organizations: Contextual, temporal, and emergent processes. In Multi-Level Theory, Research, and Methods in Organizations; Klein, K., Kozlowski, S., Eds.; Jossey-Bass: San Francisco, CA, USA, 2000; pp. 3-90.

16. Cohen, S.G.; Bailey, D.E. What makes teams work: Group effectiveness research from the shop floor to the executive suite. J. Manag. 1997, 23, 239-290. [CrossRef]

17. Colquitt, J.A.; Noe, R.A.; Jackson, C.L. Justice in teams: Antecedents and consequences of procedural justice climate. Pers. Psychol. 2002, 55, 83-109. [CrossRef]

18. West, M.A.; Farr, J.L. Innovation and Creativity at Work: Psychology and Organizational Strategies; Wiley: New York, NY, USA, 1990.

19. King, N.; Anderson, N. Innovation and Change in Organizations; Routledge: Abingdon, UK, 1995.

20. Morgeson, F.P.; Hofmann, D.A. The structure and function of collective constructs: Implications for multilevel research and theory development. Acad. Manag. Rev. 1999, 24, 249-265.

21. Bies, R.J.; Tripp, T.M.; Kramer, R.M. At the breaking point: Cognitive and social dynamics of revenge in organizations. In Antisocial Behavior in Organizations; Giacalone, R.A., Greenberg, J., Eds.; Sage Publishing House: Thousand Oaks, CA, USA, 1997.

22. Bandura, A. Aggression: A Social Learning Analysis; Prentice-Hall: Oxford, UK, 1973.

23. Felps, W.; Mitchell, T.R.; Byington, E. How, when, and why bad apples spoil the barrel: Negative group members and dysfunctional groups. Res. Organ. Behav. 2006, 27, 175-222. [CrossRef]

24. Keyton, J. Relational communication in groups. In Handbook of Group Communication Theory and Research; Gouran, D.S., Poole, M.S., Eds.; SAGE Publications: Thousand Oaks, CA, USA, 1999; pp. 192-222.

25. Folger, R.; Skarlicki, D.P. A popcorn metaphor for employee aggression. In Dysfunctional Behavior in Organizations: Violent and Deviant Behavior; Griffin, R.W., O'Leary-Kelly, A.E., Collins, J.M., Eds.; Elsevier Science: Oxford, UK; JAI Press: Oxford, UK, 1998; pp. 43-81.

26. Glomb, T.M.; Liao, H. Interpersonal aggression in work groups: Social influence, reciprocal, and individual effects. Acad. Manag. J. 2003, 46, 486-496. [CrossRef]

27. Pirola-Merlo, A.; Härtel, C.; Mann, L.; Hirst, G. How leaders influence the impact of affective events on team climate and performance in R\&D teams. Leadersh. Q. 2002, 13, 561-581.

28. Zohar, D. Safety climate in industrial organizations: Theoretical and applied implications. J. Appl. Psychol. 1980, 65, 96-102. [CrossRef] [PubMed] 
29. Ostroff, C.; Kinicki, A.J.; Tamkins, M.M. Organizational Culture and Climate; John Wiley \& Sons, Inc.: New York, NY, USA, 2003.

30. Arthur, J.B.; Herdman, A.O.; Yang, J. How a climate for incivility affects business unit performance: Testing a linkage model. Acad. Manag. Proc. 2011, 2011, 1-7. [CrossRef]

31. Gittell, J.H.; Seidner, R.; Wimbush, J. A relational model of how high-performance work systems work. Organ. Sci. 2010, 21, 490-506. [CrossRef]

32. Glaser, S.R.; Zamanou, S.; Hacker, K. Measuring and interpreting organizational culture. Manag. Commun. Q. 1987, 1, 173-198. [CrossRef]

33. Hackman, J.R. The design of work teams. In Handbook of Organizational Behavior; Lorsch, J.W., Ed.; Prentice-Hall: Englewood Cliffs, NJ, USA, 1987; pp. 315-342.

34. Jones, G.R.; George, J.M. The experience and evolution of trust: Implications for cooperation and teamwork. Acad. Manag. Rev. 1998, 23, 531-546.

35. West, M.A.; Farr, J.L. Innovation at work: Psychological perspectives. Soc. Behav. 1989, 4, 15-30.

36. Anderson, N.; King, N. Innovation in organizations. In International Review of Industrial and Organizational Psychology; Cooper, C.L., Robertson, I.T., Eds.; John Wiley \& Sons: Chichester, UK, 1993; Volume 8.

37. Anderson, N.R.; West, M.A. Measuring climate for work group innovation: Development and validation of the team climate inventory. J. Organ. Behav. 1998, 19, 235-258. [CrossRef]

38. Amabile, T.M. How to kill creativity. Harv. Bus. Rev. 1998, 76, 76-87. [PubMed]

39. Hauschildt, J.; Kirchmann, E. Teamwork for innovation-The 'troika' of promotors. RED Manag. 2001, 31, 41-49. [CrossRef]

40. Eisenberger, R.; Huntington, R.; Hutchison, S.; Sowa, D. Perceived organizational support. J. Appl. Psychol. 1986, 71, 500-507. [CrossRef]

41. Shore, L.M.; Shore, T.H. Perceived organizational support and organizational justice. In Organizational Politics, Justice, and Support: Managing the Social Climate of the Workplace; Cropanzano, R.S., Kacmar, K.M., Eds.; Quorum Books: Westport, CT, USA, 1995; pp. 149-164.

42. Wayne, S.J.; Shore, L.M.; Liden, R.C. Perceived organizational support and leader-member exchange: A social exchange perspective. Acad. Manag. J. 1997, 40, 82-111. [CrossRef]

43. Wallas, G. The Art of Thought; Solis Press: London, UK, 1926.

44. Baer, M.; Frese, M. Innovation is not enough: Climates for initiative and psychological safety, process innovations, and firm performance. J. Organ. Behav. 2003, 24, 45-68. [CrossRef]

45. Brislin, R.W. Translation and content analysis of oral and written material. In Handbook of Cross-Cultural Psychology; Triandis, H.C., Berry, J.W., Eds.; Allyn \& Bacon: Boston, MA, USA, 1980; pp. 389-444.

46. Bennett, R.J.; Robinson, S.L. Development of a measure of workplace deviance. J. Appl. Psychol. 2000, 85, 349-360. [CrossRef] [PubMed]

47. Chan, D. Functional relations among constructs in the same content domain at different levels of analysis: A typology of composition models. J. Appl. Psychol. 1998, 83, 234-246. [CrossRef]

48. James, L.R. Aggregation bias in estimates of perceptual agreement. J. Appl. Psychol. 1982, 67, $219-229$. [CrossRef]

49. Bliese, P.D. Within-group agreement, non-independence, and reliability: Implications for data aggregation and analysis. In Multi-Level Theory, Research, and Methods in Organizations; Klein, K., Kozlowski, S., Eds.; Jossey-Bass: San Francisco, CA, USA, 2000; pp. 349-381.

50. James, L.R.; Brett, J.M. Mediators, moderators, and tests for mediation. J. Appl. Psychol. 1984, 69, $307-321$. [CrossRef]

51. Preacher, K.J.; Hayes, A.F. SPSS and SAS procedures for estimating indirect effects in simple mediation models. Behav. Res. Methods Instrum. Comput. 2004, 36, 717-731. [CrossRef] [PubMed]

52. Cortina, L.M.; Kabat-Farr, D.; Leskinen, E.A.; Huerta, M.; Magley, V.J. Selective incivility as modern discrimination in organizations: Evidence and impact. J. Manag. 2013, 39, 1579-1605. [CrossRef]

53. Miner-Rubino, K.; Reed, W.D. Testing a moderated mediational model of workgroup incivility: The roles of organizational trust and group regard. J. Appl. Soc. Psychol. 2010, 40, 3148-3168. [CrossRef]

54. MacKinnon, D.P.; Lockwood, C.M.; Hoffman, J.M.; West, S.G.; Sheets, V. A comparison of methods to test mediation and other intervening variable effects. Psychol. Methods 2002, 7, 83-104. [CrossRef] [PubMed]

55. Efron, B.; Tibshirani, R.J. An Introduction to the Bootstrap; CRC Press: Boca Raton, FL, USA, 1994.

56. Schneider, B. Organizational Climate and Culture; Pfeiffer: San Francisco, CA, USA, 1990. 
57. Hofstede, G. Culture's Consequences: International Differences in Work-Related Values; SAGE Publications: Newbury Park, CA, USA, 1984; Volume 5.

58. Carton, A.M.; Cummings, J.N. A theory of subgroups in work teams. Acad. Manag. Rev. 2012, 37, 441-470. [CrossRef]

59. Penney, L.M.; Spector, P.E. Job stress, incivility, and counterproductive work behavior (CWB): The moderating role of negative affectivity. J. Organ. Behav. 2005, 26, 777-796. [CrossRef]

(C) 2016 by the author; licensee MDPI, Basel, Switzerland. This article is an open access article distributed under the terms and conditions of the Creative Commons Attribution (CC-BY) license (http://creativecommons.org/licenses/by/4.0/). 